\title{
Enhancement of heat transfer of solar air heater roughened with circular transverse RIB
}

\author{
Gurpreet Singh $^{1}$, Dr. G. S. Sidhu ${ }^{2}$ \\ Lala Lajpat Rai Institute of Engineering and Technology, Moga Punjab, India ${ }^{1,2}$
}

\begin{abstract}
An experimental investigation of the effect of geometrical parameters of circular transverse ribs on heat transfer of rectangular duct with heated plate having rib roughness on its underside have been reported. The range of parameters for this study has been decided on the basis of practical considerations of the system and operating conditions of solar air heaters. The experimental investigation encompassed the Reynolds number (Re) range from 2564 to 6206; relative roughness pitch (P/e) of 8, angle of attack $(\alpha)$ of $90^{\circ}$ and relative roughness height $(\mathrm{e} / \mathrm{Dh})$ is 0.047. The thermal efficiency of roughened duct is observed to be 5\%-9\% more as compare to the smooth duct. The thermal efficiency is increased with increasing the value of Reynolds number.
\end{abstract}

Keywords: Solar air heaters, heat transfer, thermal efficiency, Reynolds number.

\section{INTRODUCTION}

In all our daily activities energy is required such as transportation, industrial, domestic or agricultural activities. It can be used in different forms. Most of the energy comes from fossil fuels and the world fossil fuels reserves are limited. As a result of the limited extent of fossil fuels, these energy sources will need to be replaced by renewable alternatives. Solar energy is available freely, omnipresent and an indigenous source of energy provides a clean and pollution free atmosphere. The simplest and the most efficient way to utilize solar energy is to convert it into thermal energy for heating applications by using solar collectors. Solar air heaters, because of their inherent simplicity are cheap and most widely used collector devices. The efficiency of flat plate solar air heaters has been found to be low because of low heat transfer coefficient between the absorber plate and the flowing air, which increases the absorber plate temperatures, leading to higher heat losses to the environment. Hence, different modifications are suggested and applied to improve the heat transfer coefficient between the absorber plate and air. One of the methods is installation of turbulence promoters in the form of artificial roughness on the underside of the absorber plate. Such artificial roughness produces the turbulence and breaks the laminar sub layer due to this more heat transfer archived.

Solar air heaters are being used for many applications at low and moderate temperatures. Some of these are crop drying, timber seasoning, space heating, chicken brooding and curing / drying of concrete / clay building components. Han et al.[9] seen the effect of artificial roughness on heat transfer and friction factor for two opposite roughened surfaces. Verma and Prasad [13] studied the effect of protruding wires on friction factor, heat transfer coefficient and plate efficiency factor of a solar air heater , Prasad and Saini [21] studied the effect of roughness and flow parameters such as relative roughness height $(\mathrm{e} / \mathrm{D})$ and relative roughness pitch $(\mathrm{p} / \mathrm{e})$ on heat transfer and friction factor.

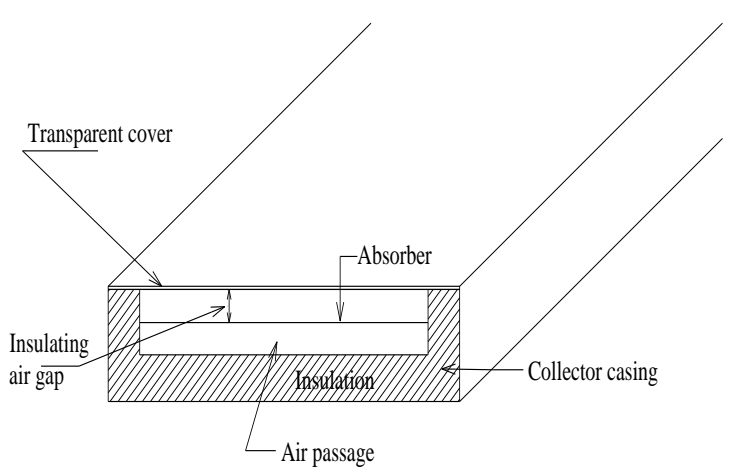

Figure 1 Conventional Flat Plate Solar Collector.

Sahu et al.[15] experimentally investigated the heat transfer coefficient by using 900 broken transverse ribs on absorber plate of a solar air heater, Gupta et al. [11] experimentally investigated the effect of relative roughness height (e/d), Aharwal et al.[17] carried out result of inclination of rib with respect to flow direction and Reynolds number $(\mathrm{Re})$ on

the thermo hydraulic performance of a roughened solar air heater for transitionally rough flow region. Lanjewar et al. [22] studied a very narrow channel $(\mathrm{AR}=8: 1)$ with $\mathrm{W}$ shaped, discrete W- shaped, v-shaped, angled ribs. Singh et al.[23] carried out the result of thermo-hydraulic performance due to flow attack angle in V-down rib with gap in the rectangular duct of solar air heater. Experimentally they found that the highest heat transfer enhancement and the highest friction losses done by Wshaped and discrete $\mathrm{W}$ - shaped roughness. In view of above literature the present experimental work conducted the range of parameters of Reynolds number 2000-14000, relative roughness height 0.036 , relative roughness pitch $8-12$, angle of attack 600 and duct aspect ratio 8. In present study, the experimental investigation of thermal performance for artificial roughened duct solar air heater has been reported. 
International Advanced Research Journal in Science, Engineering and Technology Vol. 1, Issue 4, December 2014

\section{EXPERIMENTAL SETUP AND PROCEDURE}

\section{Experimental apparatus}

In solar air heaters, the three walls of rectangular duct are smooth and insulated while only one wall i.e. absorber is explored to solar radiation. It is reported that, by using the roughness underside the absorber plate results in higher heat transfer enhancement than smooth plate. The basic experimental setup consists of duct, G.I. pipe, orifice plate, flow valve, flexible pipe, blower, etc. The ambient air is sucked by blower the rib-roughened rectangular duct. An experimental setup has been designed and fabricated for determining the thermal efficiency of roughened duct. The schematic diagram experimental setup and photograph of the experimental setup are shown in Figures 2 and 3 respectively. The detailed constructional features of air. individual components are as under; the cross-section of the rectangular duct is shown in Figure 2. The duct has
$2200 \mathrm{~mm}$ length; $520 \mathrm{~mm}$ width and $25 \mathrm{~mm}$ depth made up of galvanized iron sheet and kept inclined at angle of $45^{\circ}$ to the horizontal. The absorber plate is $1 \mathrm{~mm}$ thick galvanized iron (GI) sheet. The length of GI sheet is $1900 \mathrm{~mm}$. The two sides of duct are covered with wood having $45 \mathrm{~mm}$ thickness and bottom is insulated with 76 $\mathrm{mm}$ thick glass wool. The side of G.I sheet (absorber plate) is painted with dull black color to increases the absorber efficiency. A $4 \mathrm{~mm}$ thick glass cover is fixed above the absorber plate and wooden box is fitted like duct to place thermometer at the outlet of duct. A blower, control valve, orifice plate and other devices such as thermometer measures temperature, manometer for pressure measurement. Blower sucks the air through dcut and pipe and control valve regulate and change the flow of
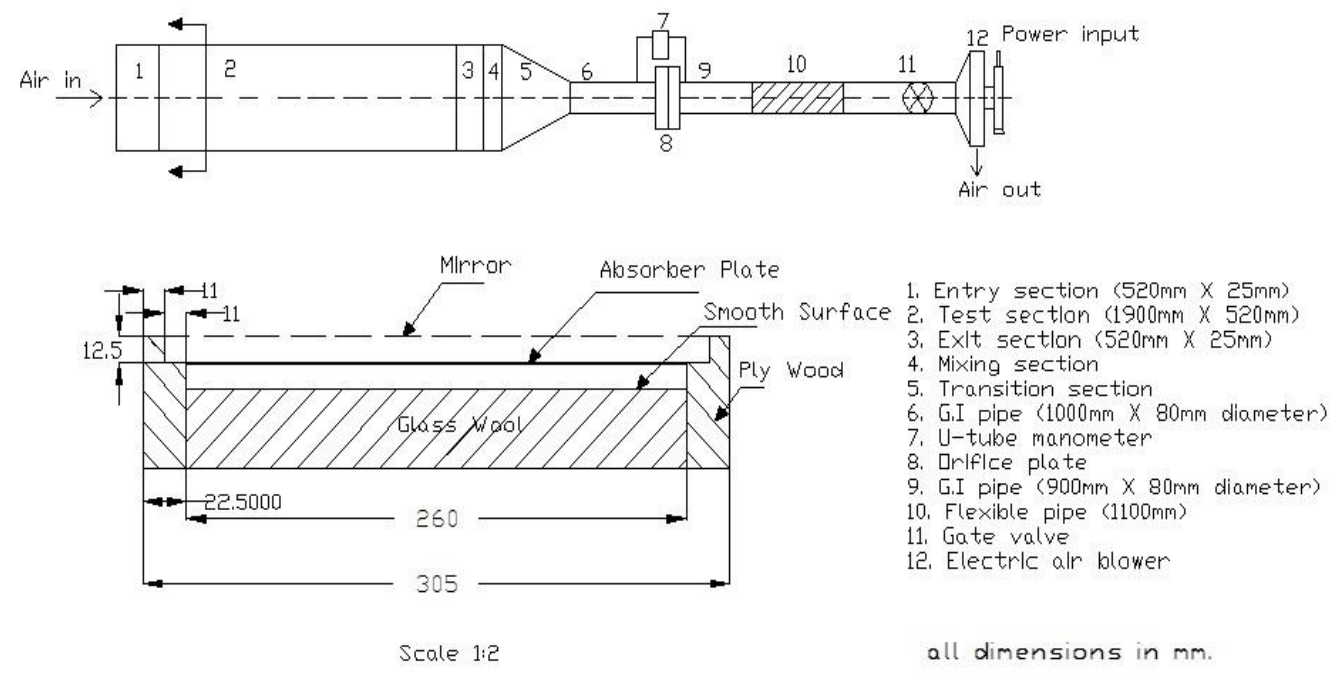

Figure 2 Schematic diagram of experimental setup.

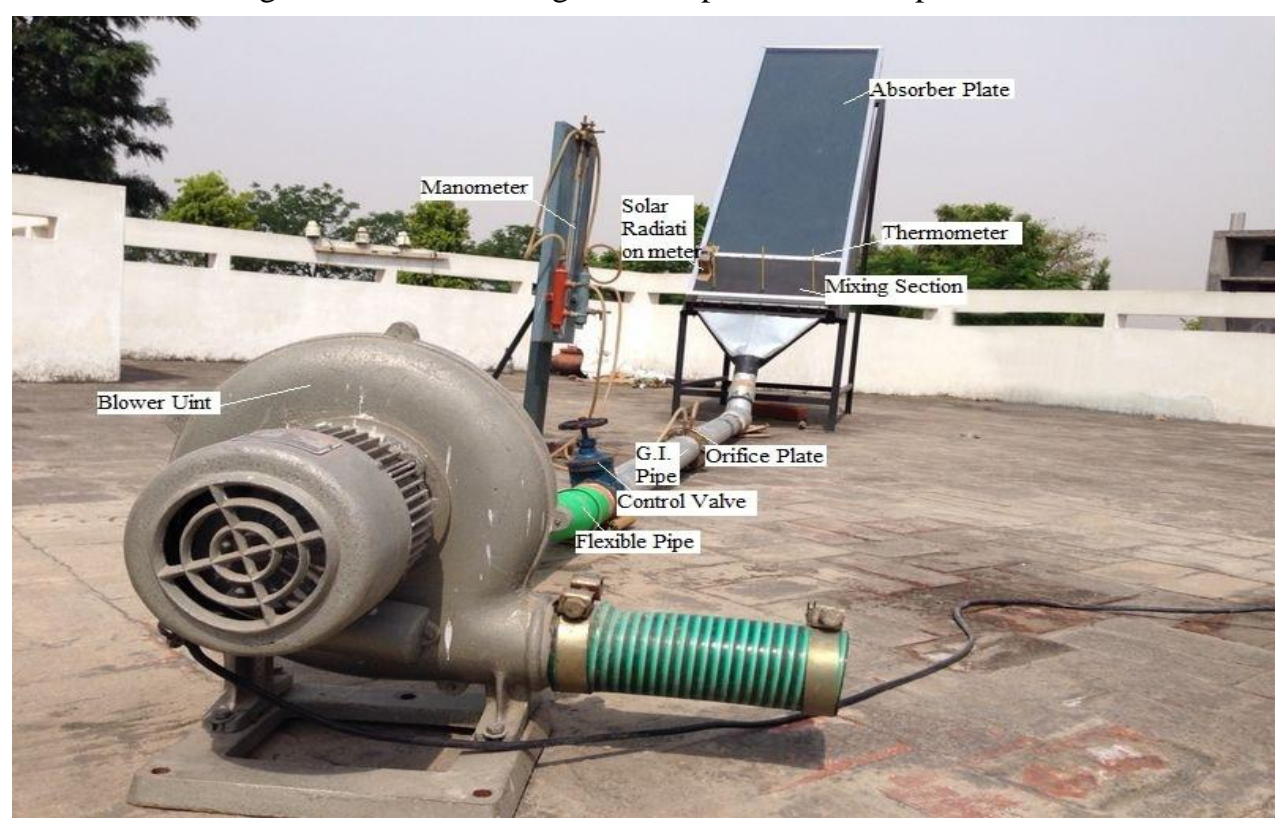

Figure 3 Photograph of the experimental setup. 


\section{Experimental procedure}

Collect all the relevant data concern with setup and required data for each rib configuration and the various Reynolds no.2564-6206. This gives the various parameters which are to be measured during

experiments. The parameters are needed to record is:

1. Inlet temperature of air at entrance of duct.

2. Outlet temperature of air at exit section of the duct.

3. Pressure drop across orifice plate measure with the help of manometer.

4. Solar intensity.

\section{Data reduction}

\section{(a) Mean temperature of air at inlet and outlet of the} duct.

The mean temperature of air outlet $\left(\mathrm{T}_{0}\right)$ by weighted average method and the temperature at inlet of duct is direct measured as ambient temperature $\left(\mathrm{T}_{\mathrm{a}}\right)$.

$\mathrm{T}_{\mathrm{a}}=$ ambient temperature $\left({ }^{\circ} \mathrm{C}\right)$

Table 1 Values of flow and roughness parameters.

\begin{tabular}{|l|l|l|}
\hline $\begin{array}{l}\text { Sr. } \\
\text { no. }\end{array}$ & Parameter & Range \\
\hline 1. & Air flow rate & $\begin{array}{l}0.011 \\
0.027 \mathrm{~kg} / \mathrm{sec}- \\
\mathrm{m}^{2}(\mathrm{Re}=2564 \text { to } \\
6206)\end{array}$ \\
\hline 2. & $\begin{array}{l}\text { Relative roughness } \\
\text { pitch }(\mathrm{P} / \mathrm{e})\end{array}$ & 8 \\
\hline 3. & Angle of attack $(\alpha)$ & $90^{\circ}$ \\
\hline 4. & $\begin{array}{l}\text { Relative roughness } \\
\text { height }(\mathrm{e} / \mathrm{Dh})\end{array}$ & 0.047 \\
\hline
\end{tabular}

$\mathrm{T}_{\mathrm{o}}=\frac{\mathrm{T}_{1}+\mathrm{T}_{2}+\mathrm{T}_{3}}{3}=\mathrm{T} 1+\mathrm{T} 2+\mathrm{T} 3 / 3$ is called mean temperature at outlet of the duct.

\section{(b) Mass flow rate of air}

Mass flow rate of air has been determined from using the following relationship:

$\mathrm{m}=\mathrm{Q} \times \rho$

Where, $\mathrm{m}$ mass flow rate of air and $\rho$ is the air density and $\mathrm{Q}$ is discharge.

Mass flow rate of air was taken according to area of the absorber plate and the ranges were between 0.011 to 0.027 $\theta 7 \mathrm{~kg} / \mathrm{sec}-\mathrm{m}^{2}$

$$
\mathrm{Q}=\mathrm{C}_{\mathrm{d}} \frac{\mathrm{A}_{1} \times \mathrm{A}_{2}}{\sqrt{\mathrm{A}_{1}^{2}-\mathrm{A}_{2}^{2}}} \sqrt{2 \mathrm{gh}_{\mathrm{a}}}
$$

Where, $\mathrm{Q}$ is a coefficient of discharge.

$\mathrm{A}_{1}$, area of plate $\mathrm{m}^{2}$.

$\mathrm{A}_{2}$, area of orifice $\mathrm{m}^{2}$.

$\mathrm{C}_{\mathrm{d}}$, coefficient of discharge assuming 0.62

$\mathrm{h}_{\mathrm{a}}=\mathrm{h}_{\mathrm{m}}\left(\frac{\rho_{\mathrm{m}}}{\rho_{\mathrm{a}}}-1\right)$
Where, $\mathrm{h}_{\mathrm{m}}$, manometric height of fluid

$\rho_{\mathrm{m}}$, Density of manometric fluid (water $1000 \mathrm{~kg} / \mathrm{m}^{2}$ )

$\rho_{\mathrm{a}}$, density of air $\mathrm{kg} / \mathrm{m}^{3}$

\section{(c) Velocity of air through duct}

The velocity of air is obtained from the calculated values of mass flow rate of air and flow area as,

$\mathrm{V}=\frac{\mathrm{m}}{\rho_{\text {air }} \mathrm{WH}}$

Where,

$\mathrm{m}=$ Mass flow rate, $\mathrm{kg} / \mathrm{sec}$

$\rho_{\text {air }}=$ Density of air in $\mathrm{kg} / \mathrm{m}^{3}$

$\mathrm{H}=$ Height of the duct in $\mathrm{m}$

$\mathrm{W}=$ Width of the duct, $\mathrm{m}$

\section{(d) Equivalent hydraulic diameter}

The hydraulic diameter of the rectangular section of the duct is determined from the relationship as given here:

$\mathrm{D}_{\mathrm{h}}=\frac{4 \times \text { aera of flow }}{\text { wetted parameter }}=\frac{4(\mathrm{WH})}{2(\mathrm{~W}+\mathrm{H})}$

\section{(e) Reynolds number $(\operatorname{Re})$}

The Reynolds number of air flow in the duct is calculated from the following relationship:

$\operatorname{Re}=\frac{\mathrm{VD}_{\mathrm{h}}}{\mathrm{v}}$

(f) Useful gain

$\mathrm{a}=\left(\mathrm{mc}_{\mathrm{p}} \Delta \mathrm{T}\right)$

\section{(g) Thermal efficiency $\left(\eta_{t h}\right)$}

$\eta_{\boldsymbol{t h}}=\frac{\text { useful gain (a) }}{\text { Radiation (b) } \times \text { Area of absorber plate }}$

\section{RESULT AND DISCUSSION}

The major objective of the present study is to determine the thermal_efficiency of solar air heater artificially roughened with transverse rib the average thermal efficiencies are presented and discussed as a function of air flow rate. Results also have been compared with the smooth duct under similar air flow rate to determine the enhancement in thermal efficiency.

The variation in thermal efficiency and temperature change corresponding to time discussed also. In case of thermal efficiency, as value of Reynolds number is increased, the thermal efficiency also increased that's observed in experiments.

Smooth; It is observed from the experimental study the thermal efficiency lies between $36 \%$ to $61 \%$ when Reynolds number value lies between 2564-6206. It is also observed that the thermal efficiency increases with increase in Reynolds number that shows in figure. 


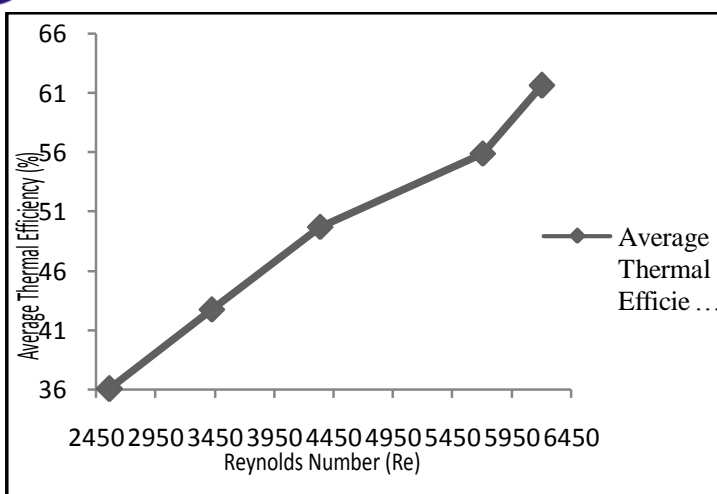

Figure 4 Variation in average thermal efficiency with respect to Reynolds number for smooth duct.

Roughened; The thermal efficiency increases by increasing the value of Reynolds number is observed in experiments. Thermal efficiency lies between $41 \%$ to $70 \%$ of roughened duct when the value of Reynolds number lies between 2564-6206.

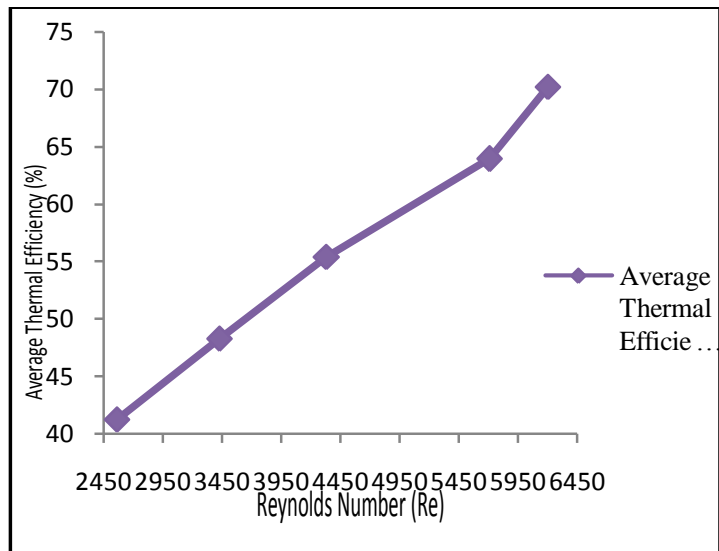

Figure 5 Variation in average thermal efficiency with respect to Reynolds number for roughened duct.

\section{Comparison}

Bar chart shows that thermal efficiency in roughened duct is more as compare to smooth duct.

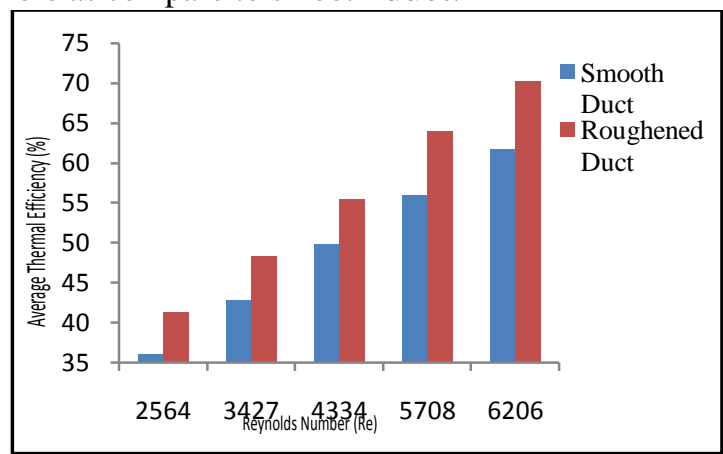

Figure 6 Comparison of average thermal efficiency with respect to Reynolds number between smooth and roughened.

The variation in thermal efficiency varies from $36 \%$ to $62 \%$ in case of smooth duct and the thermal efficiency increases $41 \%$ to $70 \%$ in roughened. The change in thermal efficiency occur with increasing the value of Reynolds number and sub layer breaks cause higher heat transfer from absorber to the flow air.

\section{CONCLUSIONS}

Presence of transverse rib on the absorber plate is an effective technique to enhance the rate of heat transfer as compared to the smooth solar air heaters. It has been found that thermal efficiency increases with the increase in Re. Breakage of laminar sub layer creates higher turbulence of air, which results higher heat transfer. The comparison between smooth and roughened surfaces at different air flow rate shows the average thermal efficiencies increases from $5 \%$ to $9 \%$.

\section{REFERENCES}

[1] H.C. Hottel, B.B. Woertz, "The performance of flat plate solar heat collectors", Trans. ASME, Vol. 64, pp.91-104, 1942.

[2] C.L. Gupta, H.P. Garg, "Performance studies on solar air heaters", Solar Energy, Vol. 11, pp.25-31, 1966.

[3] K. Selçuk, "Thermal and economic analysis of the overlapped-glass plate solar-air heater", Solar Energy, Vol. 13, pp.165-191, 1971.

[4] AME. Momin, J.S. Saini, S.C. Solanki, "Heat transfer and friction in solar air heater with v-shaped rib roughness on absorber plate", International Journal of Heat and Mass Transfer, Vol. 45, pp.3383-3396.

[5] T.A. Reddy, C.L. Gupta, "Generating application design data for solar air heating systems", Solar Energy, Vol. 25, pp.527- 530, 1980.

[6] P. Persad, S. Satcunanathan, "The thermal performance of the twopass, two glass-cover solar air heater", ASME Journal of Solar Energy Engineering, Vol. 105, pp.254-258, 1983.

[7] K. Prasad, S.C. Mullick, "Heat transfer characteristics of a solar air heater used for drying purposes", Applied Energy, Vol. 13, pp.83-93, 1983.

[8] B.N. Prasad, J.S. Saini, "Effect of artificial roughness on heat transfer and friction factor in a solar air heater", Solar Energy Vol. 41, pp.555-560, 1988.

[9] Han JC, Zhang YM, Lee CP, “Augmented heat transfer in square channels with parallel, crossed and V-shaped angledRibs", Trans ASME J Heat Transfer 113, pp.590-96,1991.

[10] J.C. Han, Y.M. Zhang, "High performance heat transfer ducts with parallel broken and V-shaped broken ribs", International Journal of Heat and Mass Transfer, Vol. 35, pp.513-523, 1992.

[11] Gupta D, Solanki SC, Saini JS, "Thermo hydraulic performance of solar air heaters with roughened absorber plates", Solar Energy, Vol. 61, pp.33-42 1997.

[12] R. Karwa, S.C. Solanki, J.S. Saini, "Heat transfer coefficient and friction factor correlations for the transitional flow regime in ribroughened rectangular ducts", International Journal of Heat and Mass Transfer, Vol. 42, pp. 1597-1615, 1999.

[13] S.K. Verma, B.N. Prasad, "Investigation for the optimal thermo hydraulic performance of artificially roughened solarair heaters", Renewable Energy, vol. 20 pp. 19-36, 2000.

[14] J.L. Bhagoria, J.S. Saini, S.C. Solanki, "Heat transfer coefficient and friction factor correlations for rectangular solar air heater duct having transverse wedge shaped rib roughness on the absorber plate", Renewable Energy, Vol.25, pp.341-369, 2002.

[15] M.M. Sahu, J.L. Bhagoria, "Augmentation of heat transfer coefficient by using $90^{\circ}$ broken transverse ribs on absorber plate of solar air heater", Renewable Energy, Vol. 30, pp. 2057-2063, 2005.

[16] A.R. Jaurker, J.S. Saini, B.K. Gandhi, "Heat transfer and friction characteristics of rectangular solar air heater duct using rib-grooved artificial roughness", Solar Energy,Vol. 80, pp.895-907, 2006.

[17] Aharwal KR, Gandhi BK, Saini JS, "Experimental investigation on heat-transfer enhancement due to a gap in an inclined continuous rib arrangement in a rectangular duct of solar air heater", Renewable Energy, Vol. 33, pp. 585-96, 2008.

[18] A. Kumar, J.L. Bhagoria, R.M. Sarviya, "Heat transfer and friction correlations for artificially roughened solar air heater duct with discrete w-shaped ribs", Energy Conversion and Management, Vol. 50, pp.2106-2117, 2009.

[19] A. Lanjewar, J.L. Bhagoria, R.M, "Sarviya Experimental study of augmented heat transfer and friction in solar air heater with different orientations of W-Rib roughness",Experimental Thermal and Fluid Science, Vol. 35, pp. 986-995,2011. 
[20] V.S. Hans, R.P. Saini, J.S. Saini, "Heat transfer and friction factor correlations for a solar air heater duct roughened artificially with multiple V-ribs", Solar Energy, Vol. 84, pp.898-911, 2010.

[21] A.R. Jaurker, Srajan Raikwar. "Evaluation of Heat transfer for artificial wedge ribbed duct over smooth duct of solar air heater", Proceeding of international conference on advances in Renewable Energy on recent trends in Mechanical engineering Maulana Azad National Institute of Technology, Bhopal, Vol. 2, 2010.

[22] A. Lanjewar, J.L. Bhagoria, R.M. Sarviya, "Heat transfer and friction in solar air heater duct with $\mathrm{w}$-shaped rib roughness on absorber plate", Energy doi:0.1016/ j.energy, 2011.

[23] Sukhmeet Singh, S. Chander, J.S. Saini, "Investigations on thermohydraulic performance due to flow-attack-angle in V-down rib with gap in the rectangular duct of solar air heater", Applied Energy, Vol. 97, pp.907-912, 2012.

[24] A. Kumar, R.P. Saini, J.S. Saini, "Development of correlation of Nusselt number and friction factor for solar air heater with roughened duct having multiple v-shaped with gap rib as artificial roughness", Renewable Energy, Vol. 58, pp.151-163, 2013. 